\title{
INTERthesis
}

\section{VIOLÊNCIA CONTRA AS MULHERES NA FRONTEIRA: AS CIDADES GÊMEAS DE CORUMBÁ/PORTO QUIJARO E PONTA PORÃ/PEDRO JUAN CABALLERO}

\author{
Luiza Vieira Sá Figueiredo $^{1}$
}

\begin{abstract}
Resumo:
No presente artigo, aborda-se a interface de duas políticas de Estado específicas, a contemplarem a fronteira e a violência contra as mulheres, decorrente de pesquisa de campo realizada no ano de 2014 em duas cidades gêmeas situadas na linha da fronteira brasileira. $O$ escopo da pesquisa consistia em verificar se existe integração entre essas políticas, se elas contemplam a realidade da população fronteiriça, se atendem de forma adequada essa população. Trata-se de pesquisa aplicada, qualitativa e exploratória, em que se utilizou levantamento bibliográfico e coleta de dados em órgãos oficiais; entrevistas com profissionais da rede de atendimento à mulher, no Brasil e nos países vizinhos, bem como visitas aos órgãos públicos respectivos, em ambos os lados da fronteira brasileira. Para a efetividade das ações preventivas e repressivas de combate à violência contra a mulher é indispensável a articulação da rede de atendimento, o que se torna um pouco mais complexo em região de fronteira seca porque essa articulação tem de necessariamente contemplar o país vizinho. A pesquisa evidencia que a cooperação internacional é um dos caminhos necessários para se garantir a eficácia das políticas públicas de proteção à mulher em região fronteiriça, porque a violência contra a mulher não tem fronteira nem nacionalidade.
\end{abstract}

Palavras-chave: Violência. Mulher. Fronteira.

\section{INTRODUÇÃO}

Apesar de os limites da fronteira brasileira já estarem definidos em tratados internacionais desde o século XV - primeiramente no Tratado de Tordesilhas (1494), posteriormente no Tratado de Madrid (1750) e após a independência dos países da América Espanhola em tratados específicos, como o Tratado de Petrópolis, com a Bolívia - foi somente no século XX que a fronteira brasileira passou a ser contemplada com políticas públicas voltadas a sua realidade.

No presente artigo, aborda-se a interface de duas políticas de Estado específicas, a contemplarem a fronteira e a violência contra as mulheres, decorrente

\footnotetext{
${ }^{1}$ Doutorado em Ciências Humanas pela Universidade de São Paulo. Pós-doutorado em Democracia e Direitos Humanos na Faculdade de Direito da Universidade de Coimbra, Coimbra, Portugal. Professora do Programa de Mestrado em Estudos Fronteiriços da Universidade Federal do Mato Grosso do Sul, Campus Pantanal e da Escola Superior da Magistratura de Mato Grosso do Sul, Campo Grande, MS, Brasil. E-mail:
}

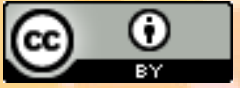
Esta obra foi licenciada com uma Licença Creative Commons - Atribuição 3.0 Não Adaptada. 
de pesquisa de campo realizada no ano de 2014 em duas cidades gêmeas situadas na linha da fronteira brasileira. O escopo da pesquisa consistia em verificar se existe integração entre essas políticas, se elas contemplam a realidade da população fronteiriça, se atendem de forma adequada essa população e, em especial, se atendem de forma adequada as mulheres dessa fronteira.

Para tanto, primeiramente far-se-á um breve histórico e contextualização da fronteira brasileira. Em seguida, uma contextualização da fronteira no Estado brasileiro de Mato Grosso do Sul para então exporem-se algumas características e projetos de duas cidades-gêmeas situadas neste Estado, no âmbito do enfrentamento da violência contra as mulheres, quais sejam, Corumbá, na fronteira com a Bolívia, e Ponta Porã, na fronteira com o Paraguai.

A pesquisa realizada pode ser classificada como aplicada, qualitativa e exploratória. Para a contextualização da fronteira brasileira e sul-mato-grossense, utilizou-se levantamento bibliográfico e coleta de dados em órgãos oficiais. Para o levantamento e análise das políticas públicas para a fronteira e de enfrentamento à violência contra a mulher, foram realizados levantamentos bibliográficos, entrevistas com profissionais da rede de atendimento, no Brasil e nos países vizinhos, bem como visitas aos órgãos públicos respectivos, em ambos os lados da fronteira brasileira.

\section{CONTEXTUALIZANDO A FRONTEIRA}

Em um breve histórico, podemos distinguir três momentos distintos para descrever a fronteira brasileira. O primeiro, caracterizado pelo desconhecimento; o segundo pela expansão e investimentos; e o terceiro e atual momento, caracterizado por um novo olhar e nova abordagem, que pretende ser coordenada e interdisciplinar.

A ocupação e povoamento do território brasileiro estiveram ligados à região litorânea e a algumas regiões do interior em razão de rios navegáveis, como algumas partes da região amazônica, por exemplo. Na década de 1860, a Guerra da Tríplice Aliança, também conhecida como Guerra do Paraguai, com a ocupação do Forte Coimbra e da cidade de Corumbá, então Estado de Mato Grosso e atual 
Estado de Mato Grosso do Sul, chamou a atenção do governo brasileiro para a fragilidade da fronteira no tocante à segurança nacional e a consequente necessidade de integração das fronteiras à região litorânea, onde estava o poder central. Passou-se, então, a investir de forma mais permanente em políticas para a integração da comunicação e do território nacional.

A segunda metade do século $X I X$ e o século $X X$ caracterizam-se pela expansão e investimentos de forma mais ordenada na região de fronteira. A partir de 1890 foram constituídas comissões telegráficas que percorreram o Estado de Mato Grosso, então uno, e parte da região amazônica, nos atuais Estados do Acre e Rondônia.

Inicialmente essas comissões tinham como finalidade estabelecer a comunicação via telégrafo dessas regiões com o governo central no Rio de Janeiro. Com o avançar dos trabalhos, essas comissões ganharam verdadeiro cunho científico. Médicos, botânicos, geólogos, naturalistas, etnógrafos passaram a acompanhar as viagens das comissões, produzindo mais de 90 relatórios científicos que retratam a riqueza natural e a diversidade dessas regiões. Esses relatórios inclusive tem dado subsídios para pesquisas recentes nas mais variadas áreas do conhecimento.

O projeto do governo central de expansão e implantação da linha telegráfica no território brasileiro foi concluído em 1915, embora trabalhos técnicos de confecção de mapas e relatórios tenham se estendido até 1930. Existem estudos que demostram que a ocupação e o povoamento dessas regiões ocorreu a partir das estações telegráficas e do traçado original da linha. Conforme aponta Bígio (2000, p. 12), os trabalhos realizados pela comissão telegráfica "serviram de referência ao traçado da antiga BR-364 e à implantação de projetos de colonização levados a efeito adiante nas décadas de 1940 e 1970 nos atuais estados de Mato Grosso do Sul, Mato Grosso e Rondônia."

Paralelo à política da integração, em 1907 foi criado o Serviço de Povoamento do Solo Nacional (BRASIL, 1907), com a finalidade de incentivar e dar subsídios para a imigração. Em relação às fronteiras, especificamente, foram criadas colônias nacionais e colônias militares na região amazônica para estimular a ocupação social e econômica dessa região.

R. Inter. Interdisc. INTERthesis, Florianópolis, v.12, n.2, p.262-278, Jul-Dez. 2015 
A demarcação de limites e fixação de marcos na fronteira esteve na agenda do Ministério das Relações Exteriores ao longo de toda a segunda metade do século XIX e primeira metade do século XX. Em 15 de janeiro de 1927 foi criada uma Comissão de Inspeção de Fronteiras, no âmbito do Ministério da Guerra, comandada pelo Marechal Cândido Mariano da Silva Rondon, com a finalidade de "proceder minuciosa inspeção das fronteiras do país, para estudar as condições de seu povoamento e segurança" (VIVEIROS, 1969, p. 491).

Essa comissão, no período de três anos, percorreu a fronteira do Brasil com Colômbia, Peru, Bolívia, Venezuela, Guiana Francesa, Guiana Holandesa, Guiana Inglesa, Paraguai, Uruguai e Argentina, passando pelos Estados brasileiros do Pará, Amazonas, Acre, Mato Grosso, Paraná e Santa Catarina (e atualmente também regiões dos Estados de Roraima, Rondônia e Mato Grosso do Sul, unidades federativas de criação mais recente). Os trabalhos da comissão não chegaram a ser concluídos, conforme previsão inicial, com a inspeção da fronteira brasileira de norte a sul, em razão do golpe de Estado que depôs o então Presidente da República Washington Luís e levou ao poder Getúlio Vargas, fato esse seguido de intensa agitação e instabilidade política.

Ao longo de todo o século $X X$ foram constituídas comissões de limites com os países vizinhos. Interessante o relato do Cônsul brasileiro no Paraguai, de que a independência das colônias espanholas complicou a questão de limites do Brasil, pois em lugar de tratar com um só Estado teve o Brasil de tratar com vários diferentes (SOUZA, 1970, p. 390-391).

Sucintamente, o que se observa acerca das questões de limites entre esses países é que não raro os acordos expressos nos tratados e convenções especiais não correspondiam a real intenção dos governos em razão da mal conhecida realidade geográfica e topográfica à época. $O$ aprofundamento de estudos geográficos e geodésicos posteriormente levou a questionamentos de interpretação e correção dos tratados e convenções já firmados. Os próprios relatórios do Ministério das Relações Exteriores apontavam a necessidade de primeiro se conhecer a região de fronteira para que se pudesse dar cumprimento ao pactuado nos tratados (BRASIL, 1924-1925). 
Em 1979 foi editada a Lei n. 6.634, que regulamenta a faixa de fronteira brasileira, conceituando-a como "a faixa de 150 quilômetros de largura, paralela à linha divisória terrestre do território nacional", sob o ponto de vista da segurança e soberania nacional. Nessa perspectiva, a legislação, ainda em vigor, traz diversas restrições nessas regiões.

Exemplificativamente, exige autorização especial para alienação e concessão de terras públicas, abertura de vias de transporte e instalação de meios de comunicação destinados à exploração de serviços de radiodifusão de sons ou radiodifusão de sons e imagens; para construção de pontes, estradas internacionais e campos de pouso; para o estabelecimento ou exploração de indústrias que interessem à Segurança Nacional, assim relacionadas em decreto do Poder Executivo e para a instalação de empresas que se dedicarem a determinadas atividades, tais como pesquisa, lavra, exploração e aproveitamento de recursos minerais, colonização e loteamento rurais; participação, a qualquer título, de estrangeiro, pessoa natural ou jurídica, em pessoa jurídica que seja titular de direito real sobre imóvel rural. Posteriormente, foi editado o Decreto n. 85.064, de 26-081980, que regulamentou a mencionada lei.

A Constituição Federal de 1988, no capítulo destinado à União, enuncia que "a faixa de até cento e cinquenta quilômetros de largura, ao longo das fronteiras terrestres, designada como faixa de fronteira, é considerada fundamental para defesa do território nacional, e sua ocupação e utilização serão reguladas em lei". Embora existam diversos projetos de lei e de emenda à Constituição que pretendam alterar o regramento sobre a fronteira, a legislação em vigor, como dito, ainda é a promulgada em 1979 e 1980.

Contudo, o avanço da tecnologia e das comunicações, o fenômeno da globalização e a tendência mundial de reunião dos países em blocos regionais, com tratados de livre comércio e circulação de pessoas, intensificados nos últimos vinte e cinco anos, mudou a realidade da fronteira brasileira. Atualmente, está-se construindo um novo olhar sobre a fronteira, repensando-se e rediscutindo-se a concepção até então predominante da fronteira como limite da linha internacional entre dois países. A fronteira passa a ser vista como um espaço de desenvolvimento estratégico e carecedor de políticas públicas especificas para essa realidade. 
Nesse contexto, em 2007, foi criado o Programa de Promoção do Desenvolvimento da Faixa de Fronteira, que tem como objetivo principal promover o desenvolvimento da faixa de fronteira por meio de sua estruturação física, social e econômica, com ênfase na ativação das potencialidades locais e na articulação com outros países da América do Sul. O programa pretende "promover a convergência das políticas públicas setoriais na faixa de fronteira, para o enfrentamento das desigualdades intra e inter-regionais, considerando a diversidade socioeconômica e cultural da região", bem como "articular a questão da soberania nacional com o desenvolvimento regional, em sua dimensão econômica, social, institucional e cultural" (BRASIL, 2008).

Atualmente, a fronteira brasileira contempla 10 dos 12 países da América do Sul; 11 dos 26 Estados da Federação; corresponde a $27 \%$ do território nacional; possui $15.719 \mathrm{~km}$ de extensão. Na faixa de fronteira existem 588 Municípios, sendo 122 na linha de fronteira. Desses 122 municípios, 29 são cidades gêmeas. A população que reside na faixa de fronteira corresponde a cerca de $5 \%$ da população brasileira. Ou seja, apesar de representar quase 1/3 do território brasileiro, a faixa de fronteira ainda é uma região pouco povoada, pois abarca somente $5 \%$ da população (BRASIL, 2008).

O Ministério da Integração Nacional publicou em 2014 uma portaria trazendo o conceito de cidade gêmea como o município cortado pela linha de fronteira, seca ou fluvial, articulada ou não por obra de infraestrutura, com grande potencial de integração econômica e cultural, conurbado ou não com uma localidade do país vizinho, que apresentem problemas característicos da fronteira, com efeitos diretos sobre o desenvolvimento regional e a cidadania. No anexo dessa portaria estão listadas as 29 cidades gêmeas. A maior concentração delas está na região Sul e em Mato Grosso do Sul na região Centro-Oeste. Nessa região, situam-se as cidades gêmeas de Corumbá/Porto Quijaro, na fronteira com a Bolívia, e Ponta Porã/Pedro Juan Caballero, na fronteira com o Paraguai. 


\title{
3 VIOLÊNCIA CONTRA AS MULHERES NA FRONTEIRA: AS CIDADES GÊMEAS DE CORUMBÁ/PORTO QUIJARO E PONTA PORÃ/PEDRO JUAN CABALLERO
}

A violência é uma calamidade mundial. Strey (s/d, p. 47) destaca que essa palavra tem sido usada para expressar "comportamentos, modos de vida, sociedades e outros fenômenos humanos". Dentre as diversas vertentes de pesquisa e estudos da violência, alguns grupos de vulnerabilidade se destacam no interesse acadêmico pela repercussão que possuem na sociedade como um todo. A violência de gênero é uma delas. Gênero "é a forma culturalmente elaborada que a diferença sexual toma em cada sociedade, e que se manifesta nos papeis e status atribuídos a cada sexo e constitutivos da identidade sexual dos indivíduos" (STREY, 2001, p. 49). Esses papeis são culturalmente elaborados e, por isso, atribuídos e adquiridos.

Para Saffioti (2004, p. 69), a violência de gênero é uma categoria de violência mais abrangente que abarca a violência doméstica e a violência intra-familiar. Strey destaca três correntes teóricas que procuram explicar a violência contra a mulher:

\begin{abstract}
[...] a primeira, que denominamos de dominação masculina, define violência contra as mulheres como expressão de dominação da mulher pelo homem, resultando na anulação da autonomia da mulher, concebida tanto como "vítima" quanto como "cúmplice" da dominação masculina; a segunda corrente, que chamamos de dominação patriarcal, é influenciada pela perspectiva feminista e marxista, compreendendo violência como expressão do patriarcado, em que a mulher é vista como sujeito social autônomo, porém historicamente vitimada pelo controle social masculino; a terceira corrente, que nomeamos de relacional, relativiza as noções de dominação masculina e vitimização feminina, concebendo violência como uma forma de comunicação e um jogo do qual a mulher não é "vítima" senão "cúmplice".
\end{abstract}

Estabelecidas tais premissas, cumpre destacar que a pesquisa realizada, buscou identificar a estruturação da rede de atendimento à mulher nas cidades estudadas de modo a avaliar se existe integração entre as políticas existentes para a fronteira e para a mulher e se elas contemplam a realidade da população fronteiriça. Deve-se registrar também que a escolha dos municípios se deu por serem os maiores em Mato Grosso do Sul na fronteira com a Bolívia (Corumbá) e com o Paraguai (Ponta Porã), representativos, portanto, da realidade que se pretendia conhecer.

R. Inter. Interdisc. INTERthesis, Florianópolis, v.12, n.2, p.262-278, Jul-Dez. 2015 
O município de Corumbá, na fronteira seca Brasil-Bolívia, é cidade gêmea. Do outro lado da linha internacional está Porto Quijaro, a cerca de 3km, e Porto Soares, a cerca de $13 \mathrm{~km}$. A população fronteiriça gira em torno de 150 mil habitantes, conforme dados estimativos do IBGE e do Ministério das Relações Exteriores. A rede de atendimento à mulher no município contempla um centro especializado de atendimento a mulher (CRAM), bem como uma delegacia especializada de atendimento a mulher (DAM). No sistema de Justiça (Poder Judiciário, Ministério Público e Defensoria Pública), existe a especialização da competência e da atribuição de uma unidade judicial ( $2^{\mathrm{a}}$ vara criminal), mas ela não é exclusiva, ou seja, dividem-se os feitos decorrentes de violência contra a mulher com a com competência criminal "comum".

$\mathrm{Na}$ linha da fronteira, existe uma estrutura da Receita Federal, com um posto da Polícia Federal, do lado brasileiro e também do lado boliviano, separadas por uma pequena ponte. As cidades, embora gêmeas, não estão propriamente conurbadas.

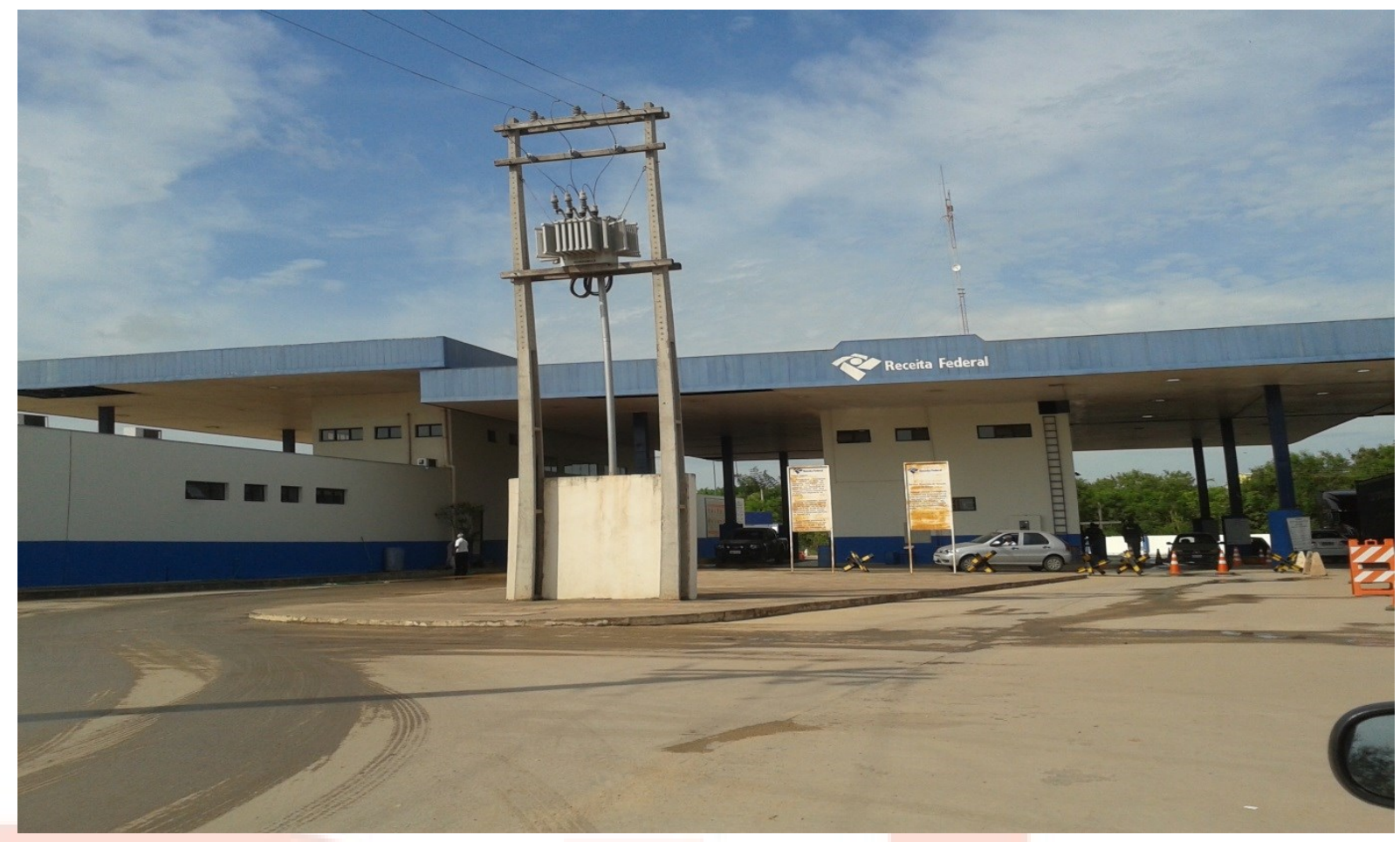

Figura 1: O lado brasileiro da fronteira Brasil-Bolívia em Corumbá Fonte: Foto do acervo pessoal da autora 


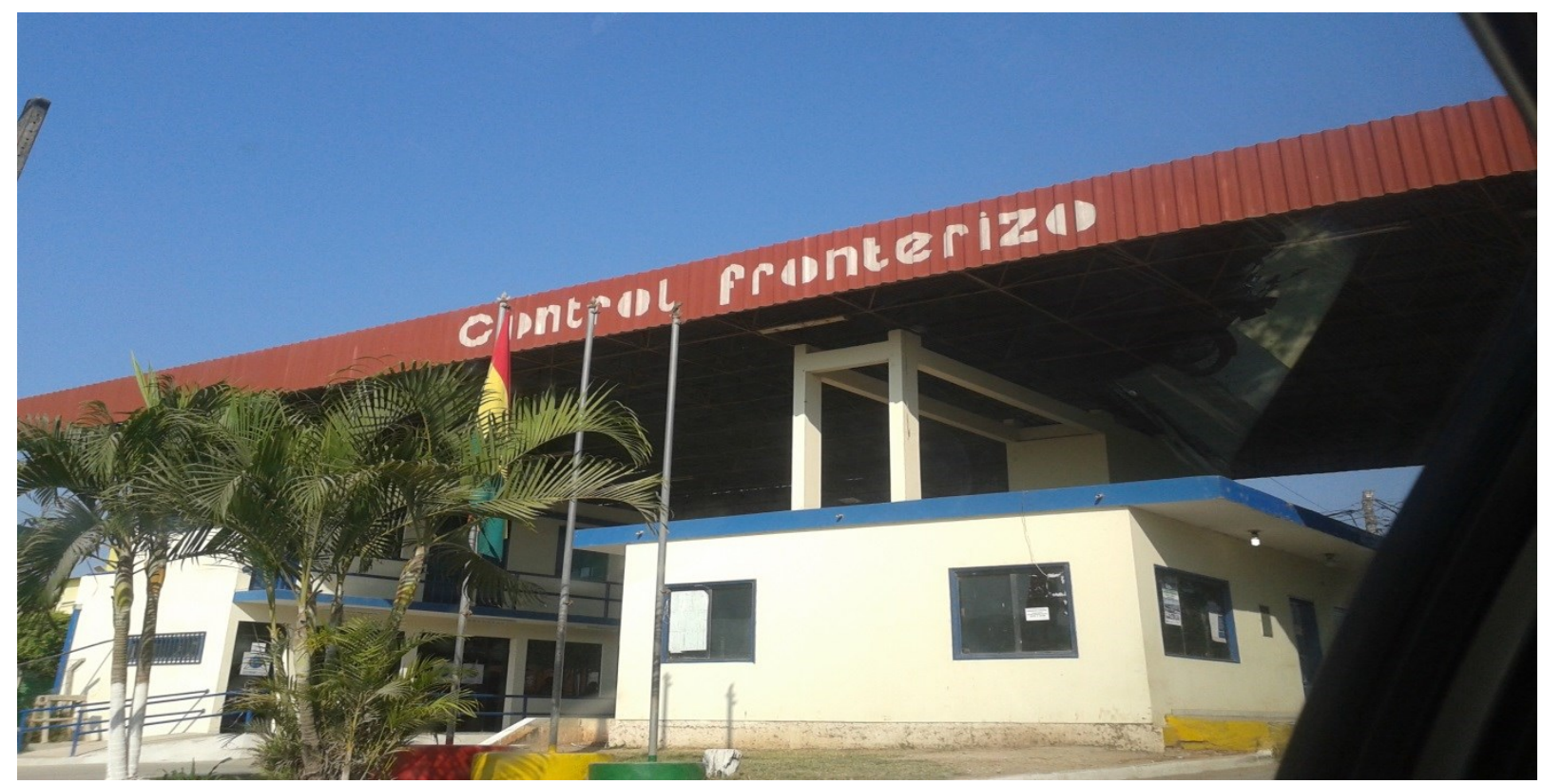

Figura 2: O lado boliviano da fronteira Brasil-Bolívia em Corumbá

Fonte: Foto do acervo pessoal da autora

Uma característica dessa região é a configuração de famílias binacionais, em que um dos cônjuges é estrangeiro - e aqui existe tanto a situação de mulheres brasileiras que residem na Bolívia quanto de mulheres bolivianas que residem no Brasil. A condição de estrangeira aparece na pesquisa como mais um ponto de vulnerabilidade dessas mulheres. Os autores de violência dizem que elas não tem direito a nada porque são estrangeiras (e aqui se contemplam diversas questões, tais como guarda de filhos, posse e partilha de bens comuns, permanência em emprego, etc.). O desconhecimento de seus direitos como estrangeiras acaba, muitas vezes, contribuindo para a perpetuação da situação de violência, seja ela psicológica, verbal ou física. Não raro o ciclo se encerra na Delegacia de Polícia, após ato de grave violência física, onde essa mulher estrangeira é esclarecida sobre seus direitos e encaminhada ao Centro de Referência (CRAM) e/ou à Defensoria Pública, que propõe as ações judiciais pertinentes ao caso. De acordo com o CRAM, pouquíssimas mulheres estrangeiras solicitam auxílio para retornar ao seu país, pois já possuem vínculos em território brasileiro, geralmente filhos e tr abalho - este último, normalmente informal no comércio).

Outra característica dessa fronteira é a alternância de domicílio, seja da mulher, do autor do fato delituoso ou de testemunhas, o que dificulta a instrução 
tanto dos procedimentos policiais quanto dos processos judiciais. Isso é comum por questões familiares, de trabalho ou emprego, ou até mesmo em busca de condições mais econômicas de custo de vida. Nessa fronteira, por exemplo, o custo de vida é menor na cidade gêmea boliviana, mas a cidade gêmea brasileira oferece melhor estrutura de serviços, especialmente médicos e educacionais, bem como oportunidades comerciais decorrentes do turismo.

A cooperação jurídica internacional, embora tenha havido muitos avanços, em especial com o auxílio do Conselho Nacional de Justiça, ainda é demorada e burocrática para a celeridade que se espera dos feitos que envolvem violência contra a mulher. Além disso, a prescrição é um grande vilão, em razão das penas cominadas aos crimes que ocorrem com maior frequência, como ameaça, lesão corporal e crime contra honra. A concessão das medidas protetivas tem sido efetivas. Às vezes no mesmo dia do registro da ocorrência o oficial de justiça intima a mulher da concessão da medida. Entretanto, o município anseia a instalação de uma vara com competência exclusiva para tratar das questões envolvendo violência contra a mulher. Não apenas o sistema de justiça (Poder Judiciário), mas sobretudo, a rede de atendimento (Poder Executivo), o que seria oportuno inclusive em razão da instalação do centro de atendimento às mulheres nas regiões de fronteira seca, informalmente referido como "Casa da Mulher da Fronteira".

O centro faz parte de um Programa do Governo Federal - Mulher: viver sem violência. A casa, que já possui terreno doado pelo Município de Corumbá, em local próximo ao centro da cidade e com fácil acesso a transporte público, reunirá os serviços da rede de atendimento e, por ser específica para a fronteira, contemplará também um serviço especializado para tráfico de mulheres e para atender a vulnerabilidade da mulher migrante. Nesse ponto, cumpre destacar ser extremamente oportuna a instalação da casa em Corumbá. Uma pesquisa feita no âmbito da Estratégia Nacional de Segurança Pública nas Fronteiras (ENAFRON) levantou um diagnóstico sobre tráfico de pessoas nas áreas de fronteira e constatouse que Corumbá é rota para o tráfico de pessoas, sugerindo-se a instalação de um posto de atendimento na cidade. A casa vem atender, então, a mulher nessa condição degradante, evidenciando, nesse ponto, a convergência das políticas. 
Uma questão que aparece na pesquisa diz respeito à estrutura dos órgãos da segurança pública para o eficaz atendimento à violência contra a mulher. Em Corumbá, especificamente, existe o fator da extensão territorial do município e a dificuldade de acesso a algumas regiões, especialmente em razão das cheias do ecossistema Pantanal. A questão de aparelhamento físico, especialmente com veículos, camionetes traçadas e barcos já foi minimizada com a doação desses equipamentos pelo governo federal, mas subsiste a questão dos recursos humanos. A falta de efetivo às vezes chega a ser gritante, com dificuldade para, por exemplo, manter o plantão policial e realizar uma diligência de campo para uma investigação criminal, que pode durar alguns dias em razão do acesso a algumas regiões mais distantes e, dependendo da época do ano, alagadas.

Ainda no âmbito dessa fronteira seca, cumpre destacar também o Projeto Justiça Sobre as Águas, do Tribunal de Justiça de Mato Grosso do Sul, através da Coordenadoria Estadual da Mulher em Situação de Violência, que foi contemplado com recursos da Secretaria de Políticas Publicas para a Mulher da Presidência da República e prevê a aquisição de um barco para atendimento ao longo das regiões ribeirinhas do Rio Paraguai em viagens periódicas, através de convênio com a Marinha em Ladário/MS, cidade vizinha a Corumbá/MS. Estima-se que haja uma grande demanda reprimida nessas regiões, algumas delas de difícil acesso à sede do Município.

A rede de atendimento em Corumbá desenvolve ainda projetos de orientação e prevenção, como o Maria da Penha visita sua Escola e Homem que respeita a mulher não bate. Trabalham a prevenção e a conscientização de públicos específicos, respectivamente, indivíduos em formação e o público masculino, com palestras sobre a Lei Maria da Penha. Em Corumbá, o projeto Homem que respeita a mulher não bate esteve no Exército, nos Correios e na Empresa Mineradora Vale do Rio Doce, instituições com grande concentração de homens em seus quadros.

No outro lado da linha internacional, especificamente em Porto Soares, também existe um serviço especializado e lei específica para combater a violência contra a mulher, a Lei n. 348 de 9 de março de 2013. São feitos trabalhos de divulgação da legislação, mas de acordo com o relato da rede boliviana de atendimento à mulher, esses trabalhos ainda são de pouca abrangência. É preciso 
avançar nesse aspecto. Interessante destacar que existe uma ONG em Porto Soares chamada "Pro Mulher", que presta auxílio financeiro para as mulheres que desejam alcançar independência financeira através de pequenos negócios.

Em relação às iniciativas de cooperação internacional, apesar da lei especifica boliviana, que é bem parecida com a brasileira no tocante às medidas cautelares, houve apenas um evento conjunto entre as redes de atendimento à mulher, realizado em 2013 com o auxílio do Consulado brasileiro em Porto Soares. Apesar da ampla divulgação desse evento, pouquíssimas mulheres compareceram. De acordo com o relato da rede boliviana de atendimento à mulher, o principal desafio é vencer os padrões culturais. Relataram a indignação de uma sogra com a nora, porque ela havia denunciado o marido por agressão e ele estava preso. A indignação não decorrida da prisão do filho, mas do fato de que ela (sogra) havia convivido o marido "sem reclamar" por mais de trinta anos, como se isso fosse uma virtude sua e a busca pela rede de atendimento uma fraqueza da nora.

$\mathrm{Na}$ fronteira Brasil-Paraguai em Mato Grosso do Sul, a pesquisa evidenciou algumas características e problemas semelhantes, embora sejam fronteiras distintas. Ou seja, alguns problemas se repetem, mas a fronteira possui características diferentes em alguns pontos.

Ponta Porã é cidade gêmea, fronteira seca. Do outro lado da linha internacional está Pedro Juan Caballero. A população fronteiriça gira em torno de 200 mil habitantes, conforme dados estimativos do IBGE e do Ministério das Relações Exteriores. 


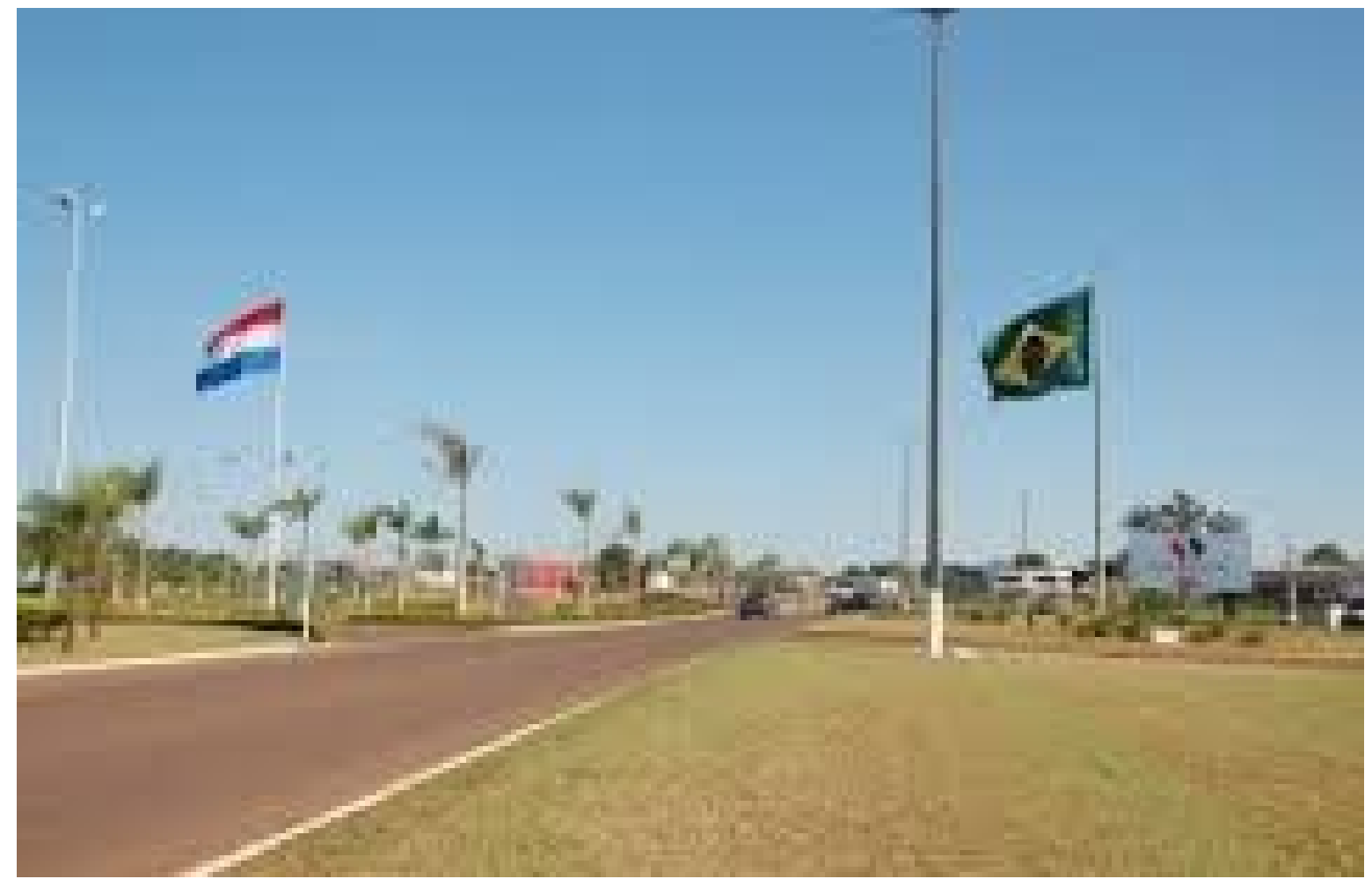

Figura 3: Fronteira Brasil-Paraguai em Ponta Porã/Pedro Juan Caballero Fonte: www.google.com.br

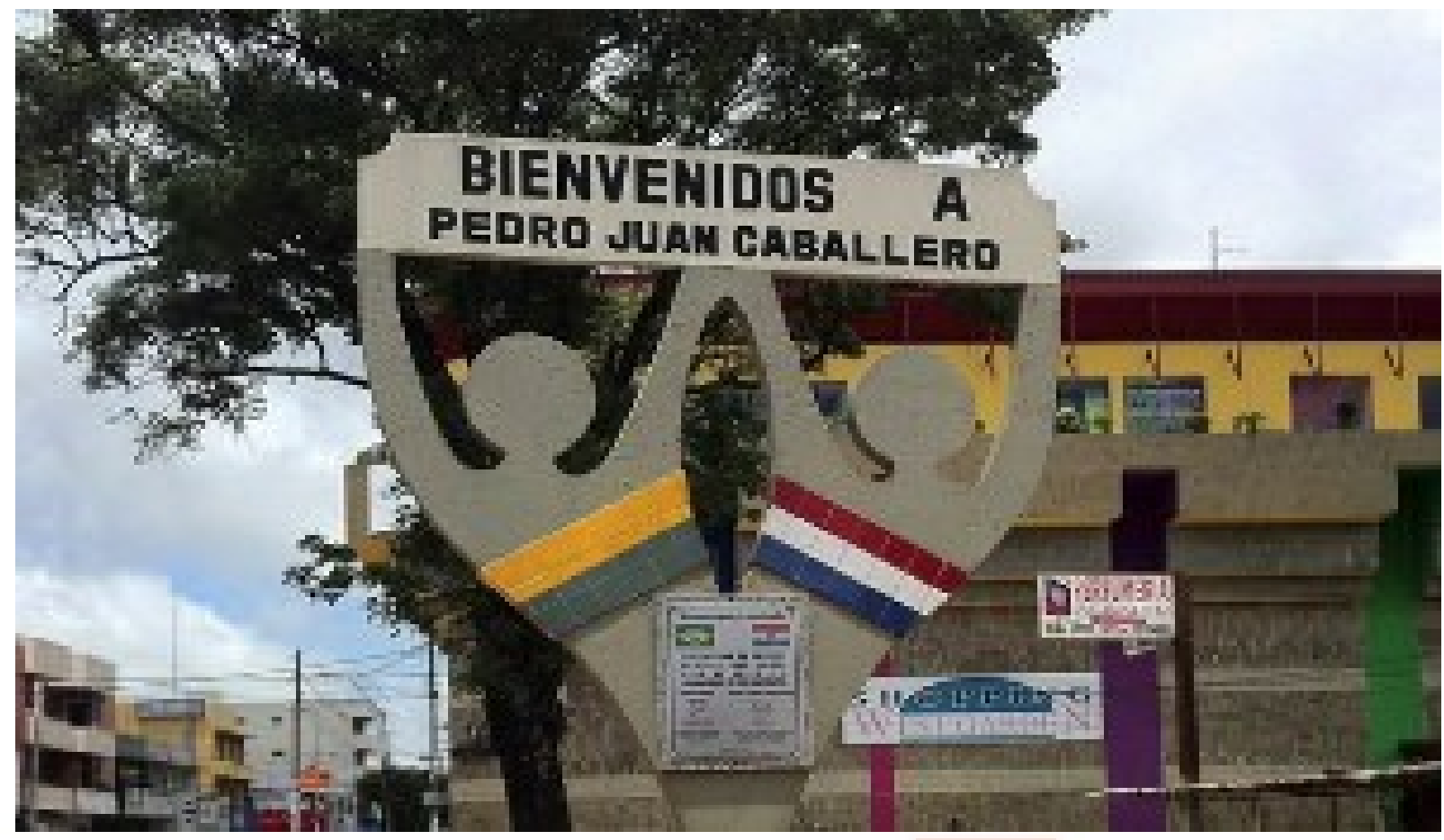

Figura 4: Fronteira Brasil-Paraguai em Ponta Porã/Pedro Juan Caballero Fonte: www.google.com.br

R. Inter. Interdisc. INTERthesis, Florianópolis, v.12, n.2, p.262-278, Jul-Dez. 2015 
A rede de atendimento à mulher em situação de violência no município contempla um centro especializado de atendimento, bem como uma delegacia especializada de atendimento à mulher. No sistema de Justiça (Poder Judiciário, Ministério Público e Defensoria Pública), tal como em Corumbá, existe a especialização da competência e da atribuição, mas ela não é exclusiva, divide-se com competência criminal (afeta à $2^{a}$ vara criminal). Diferente de Corumbá, em que existe uma estrutura da Receita Federal, com um posto da Polícia Federal na linha de fronteira, do lado brasileiro e também do lado boliviano, Ponta Porã e Pedro Juan Caballero estão conurbadas, ou seja, separadas apenas por uma avenida.

Também é característica da região a existência de famílias binacionais, em que um dos cônjuges é estrangeiro - e aqui também existe tanto a situação de mulheres brasileiras que residem no Paraguai quanto de mulheres paraguaias que residem no Brasil. A condição de estrangeira igualmente aparece na pesquisa como vulnerabilidade que contribui para a perpetuação da situação de violência, seja ela psicológica, verbal ou física. A alternância de domicílio, seja da mulher, do autor do fato delituoso ou de testemunhas, também ocorre nessa fronteira, o que dificulta a continuidade dos atendimentos pelo centro de referência, bem como a instrução tanto dos procedimentos policiais quanto dos processos judiciais.

Diferentemente da fronteira boliviana, aqui a fronteira é usada como fuga. Existem relatos de autores de violência contra mulheres em Ponta Porã que cruzaram a linha internacional para escapar de prisão em flagrante ou de responsabilização criminal. Isso tem sido minimizado pela aproximação, ainda informal, dos serviços de atendimento à mulher em Ponta Porã e em Pedro Juan Caballero, que contactam as respectivas polícias e agem em conjunto.

Há necessidade de melhor estruturação da segurança pública no município, em especial no tocante aos recursos humanos, o que aparece na pesquisa como uma fragilidade do sistema que dificulta o combate à violência contra a mulher. Ponta Porã igualmente terá um centro de atendimento às mulheres nas regiões de fronteira seca, como parte do Programa Mulher: viver sem violência. Inclusive já se iniciaram as tratativas para a criação de um comitê binacional para o enfrentamento da violência contra a mulher, o que ainda não ocorreu em Corumbá. Com efeito, a rede de atendimento à mulher, em todos os níveis, está mais articulada a nível 
binacional em Ponta Porã do que em Corumbá, talvez pela própria conurbação das cidades gêmeas na fronteira paraguaia.

O Paraguai possui lei específica de combate à violência contra a mulher, qual seja, a Lei n. 1.600/2000, e, como dito, em Pedro Juan Caballero existe um serviço especializado de atendimento à mulher. Os órgãos brasileiro e paraguaio nessa fronteira já estão em pleno contato e existem relatos inclusive de prisões efetuadas, com o auxílio das respectivas polícias, acionadas pelo centro de atendimento, bem como de resgates de mulheres em situação de cárcere privado em ambos os lados da fronteira.

\section{CONSIDERAÇÕES FINAIS}

A fronteira é uma região de trocas que agregam uma bagagem social e cultural específica, com potencialidades que devem ser identificadas e desenvolvidas em um contexto fronteiriço, independente da linha internacional de cada país. Nessa perspectiva, estamos apenas iniciando uma política para a fronteira. Pesquisas estão sendo realizadas em nível federal, estadual e municipal, com informações que contribuem para alimentar essas políticas, que devem ser específicas. Em Corumbá, por exemplo, na Universidade Federal de Mato Grosso do Sul, existe um mestrado profissionalizante em estudos fronteiriços, de caráter interdisciplinar, em que o projeto de pesquisa deve ser voltado para a fronteira, deve trazer uma problemática da fronteira, nas mais diversas áreas do conhecimento.

Para a efetividade das ações preventivas e repressivas de combate à violência contra a mulher é indispensável a articulação da rede de atendimento. $E$ isso não é novidade. Mas quando se está em região de fronteira, essa questão se torna um pouco mais complexa porque a articulação tem de necessariamente contemplar o país vizinho. Torna-se indispensável a conjugação de esforços para ações em parceria de ambas as nações para proteção, acolhimento e responsabilização dos autores de violência contra a mulher. A experiência de Ponta Porã evidencia que a cooperação internacional é um dos caminhos necessários para se garantir a eficácia das políticas públicas de proteção à mulher em região fronteiriça, porque a violência contra a mulher não tem fronteira nem nacionalidade. 


\title{
VIOLENCE AGAINST WOMEN ON BORDERS: THE TWIN CITIES OF CORUMBÁ/PORTO QUIJARO AND PONTA PORÃ/PEDRO JUAN CABALLERO
}

\begin{abstract}
:
The present paper deals with two specific state policies interfaces to contemplate the border and violence against women, due to field research held in the year 2014 in the twin cities located in the Brazilian border line. The scope chosen on the research was to ascertain whether there is integration of these policies, if they contemplate the reality of the border population, and if they adequately serve this population. It was applied a qualitative exploratory study, in which we used literature and data collection in official agencies, interviews with professionals in the treatment of women network in Brazil and neighboring countries, as well as visits to the respective government agencies on both sides of the Brazilian border. For the effectiveness of preventive and repressive actions against women violence, it is essential the service network articulation, which is something that becomes a little more complex in dry border regions because this articulation must necessarily contemplate the neighboring country. The research shows that international cooperation is one of the paths needed to ensure the effectiveness of public policies of women protection in the border region, because violence against women has no borders or nationality.
\end{abstract}

Keywords: Violence. Women. Border.

\section{VIOLENCIA CONTRA LAS MUJERES EN LA FRONTERA: LAS CIUDADES GEMELAS DE CORUMBÁ/PORTO QUIJARO Y PONTA PORÃ/PEDRO JUAN CABALLERO}

\section{Resumen:}

En el presente artículo, se aborda la interfaz de dos políticas de Estado específicas, para contemplar la frontera y la violencia contra las mulheres, consecuente de una investigación de campo realizada el año 2014 en dos ciudades gemelas situadas em la línea da frontera brasileña. El foco de la investigación consistió en verificar si existe integración entre esas políticas, si ellas contemplan la realidad de la población fronteriza, si atienden de forma adecuada a esa población. Se trata de una investigación aplicada, cualitativa y exploratoria, en que se realizó un reconocimiento de la bibliografía y una colecta de datos en órganos oficiales; entrevistas con profesionales da redes de atendimiento a la mujer, en Brasil y en los países vecinos, bien como visitas a los órganos públicos respectivos, a ambos lados de la frontera brasileña. Para la efetividad de las acciones preventivas y represivas de combate a la violencia contra la mujer es indispensable la articulación de la red de atendimiento, lo que se torna un poco más complejo en región de frontera seca, porque esa articulación tiene que contemplar al país vecino, necesariamente. La investigación evidencia que la cooperación internacional es uno de los caminos necesarios para garantizarse la eficácia de las políticas públicas de protección a la mujer en región fronteriza, porque la violencia contra la mujer no tiene fronteras ni nacionalidad.

Palavras clave: Violencia. Mujer. Frontera. 


\section{REFERÊNCIAS}

BÍGIO, E. dos S. Cândido Rondon: a integração nacional. Rio de Janeiro:

Contraponto: Petrobrás, 2000.

BRASIL, MINISTÉRIO DAS RELAÇÕES EXTERIORES. Relatório de 1924-1925.

Rio de Janeiro: Imprensa Nacional.

BRASIL, MINISTÉRIO DA INTEGRAÇÃO NACIONAL. Disponível em:

www.integração.gov.br Acesso em 15 nov. 2014

BRASIL, Decreto n. 6.455 de 19/04/1907. Disponível em:

www.presidencia.gov.br/legislação Acesso em 15 nov. 2014

BRASIL, MINISTÉRIO DA INTEGRAÇÃO NACIONAL. PROGRAMA DESENVOLVIMENTO FAIXA DE FRONTEIRA. Disponível em:

www.integração.gov.br Acesso em 15 nov. 2014

SAFFIOTI, H. I. B. Gênero, Patriarcado, Violência. São Paulo: Fundação Perseu Abramo, 2004.

SANTOS, C. M.; IZUMINO, W. P. Violência contra as Mulheres e Violência de Gênero: Notas sobre Estudos Feministas no Brasil. Disponível em:

http://eial.tau.ac.il/index.php/eial/article/view/482/446 Acesso em 09 out 2015

SOUZA, J. A. S. de. A Missão Bellegarde Ao Paraguai. Volume III. Ministério das Relações Exteriores, 1970.

STREY, M. N. Violência e gênero: um casamento que tem tudo para dar certo. In Violências e Gênero: coisas que a gente não gostaria de saber. GROSSI P. K.; WERBA, G. C. (Orgs).Porto Alegre: EDIPUCRS, 2001.

VIVEIROS, E. de. Rondon conta sua vida. Cooperativa Cultural dos Esperantistas. GB: Rio de Janeiro. 1969.

\section{Artigo}

Recebido em 30 de janeiro de 2015

Aceito em 03 de novembro de 2015

R. Inter. Interdisc. INTERthesis, Florianópolis, v.12, n.2, p.262-278, Jul-Dez. 2015 